\title{
Self-Cleaning Properties of Cellullosic Fabrics (A Review)
}

\author{
Mariam Diaa ${ }^{1}$, Ahmed G. Hassabo 2,* (D) \\ 1 Textile Printing, Dyeing and Finishing Department, Faculty of Applied Arts, Benha University, Benha, Egypt \\ 2 National Research Centre (Scopus affiliation ID 60014618), Textile Industries Research Division, Pretreatment, and \\ Finishing of Cellulose-based Textiles Department, 33 El-Behouth St. (former El-Tahrir str.), Dokki, P.O. 12622, Giza, \\ Egypt \\ * Correspondence: aga.hassabo@hotmail.com (A.G.H.);
}

Scopus Author ID: 55909104700

Received: 23.03.2021; Revised: 10.05.2021; Accepted: 12.05.2021; Published: 10.06.2021

\begin{abstract}
This article provides an overview of a technology of photocatalytic self-cleaning of fabric that is a photocatalyst like $\left(\mathrm{ZnO}\right.$ or $\mathrm{TiO}_{2}$ or other materials $)$ that decomposes organic stain into water and carbon dioxide $\left(\mathrm{CO}_{2}\right)$ in the presence of a UV light source. In this article, the photocatalytic techniques are presented. In various applications like textiles, which usually are used in everyday life, the self-cleaning principle is useful. These technologies can also be developed in other applications such as medical textiles, athletic wear, military uniforms, and outdoor fabrics. It is also desirable because it efficiently conserves water and enhances the appearance of the atmosphere and decreases energy in the long term, laundry cost and time as well
\end{abstract}

Keywords: self-cleaning; coatings; cotton fabric.

(C) 2021 by the authors. This article is an open-access article distributed under the terms and conditions of the Creative Commons Attribution (CC BY) license (https://creativecommons.org/licenses/by/4.0/).

\section{Introduction}

There are various innovations available in the world today. From nature, one of them is self-cleaning technology. Many examples include the wing of butterflies and plant leaves like cabbage and lotus.

To function, the natural fiber absorption and/or penetration of functionality of polymeric materials on/into fiber surfaces will be advantageous to confer high-performance properties on natural fibers [1-9].

Due to the wide variety of applications like cleaning the windows, solar panels, and cement; This technology gained much attention. In textiles, there are lots of developments to make self-cleaning coatings that are effective and sustainable.

This technology also provides a wide variety of applications, different benefits, including minimized operating costs, removal of tedious manual effort, and time-saving, Expended on the job of washing [10]. It can normally be categorized as hydrophobic or hydrophilic. The first includes the coating of a hydrophobic film on fabric to eliminate water droplets that contain pollutants. The surfaces of hydrophobic and superhydrophobic have a tightly arranged structure. The hydrophilic technique is not strictly dependent on water flowing to remove pollutants. Instead, photocatalytic oxidation is utilized, enabling photodegraded organic pollutants materials to be extracted all across the water surface.

The susceptibility of the solvents does not typically constrain the design of photocatalytic surfaces, and therefore has greater functional ability than the hydrophobic 
technique. Titanium dioxide $\left(\mathrm{TiO}_{2}\right)$, zinc oxide $(\mathrm{ZnO})$, and tungsten trioxide $\left(\mathrm{WO}_{3}\right)$ were used as photocatalysts $[11,12]$.

\section{Contact Angle}

The phenomena of self-cleaning rely on the surface contact Angle. This angle is found between the drop liquid surface and the surface of the fabric. The solid surface is considered a hydrophilic surface when the contact angle is lower than 90. The surface is known as a hydrophobic surface if the contact angle (CA) is above 90. Equally, a water contact angle surface-reaching zero is known as ultra-hydrophilic (super) and a contact-angle surface above150 is typically defined as hydrophobic ultra (super) (see Figure 1) [10,13].

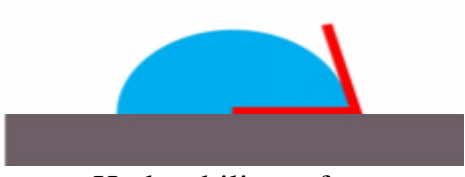

Hydrophilic surface

Contact angle $<90^{\circ}$

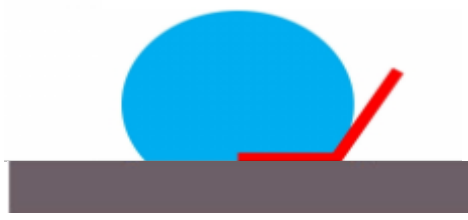

hydrophobic surface

Contact angle $>90^{\circ}$

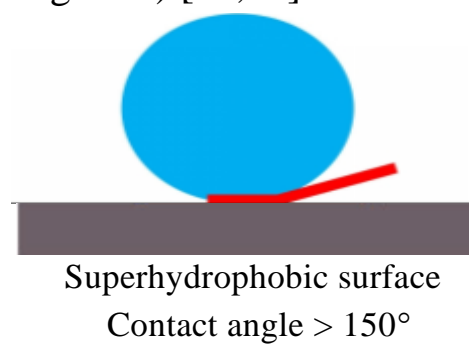

Contact angle $>150^{\circ}$

Figure 1. The contact angle of hydrophilic, hydrophobic, and superhydrophobic surface.

\section{Lotus Effect}

Nanosized wax papillae upon this top part of each epidermal cell give the lotus (Nelumbo nucifera) leaf and flower their water-repellent surface. As the reason, raindrops create a high contact angle through the papillae and rolling off, bringing stains and dust with them but keeping the surface clean. Such a self-cleaning effect, called the lotus impact, has given a chance to produce superhydrophobic surfaces for various items. Their surfaces are highly hydrophobic.

Lotus is considered a special plant in Hinduism, botanically called "Nelumbo nucifera". Lotus is also the national flora of India and is considered a sign of pureness. Its flower and leaves are disturbing to water.

A raindrop that falls becomes a water drop and carries the dust particles with it. So the lotus leaf's surface remains fairly clean while it grows in muddy waters. Even though the repellent water of the lotus is well known, But in 1997, when two scientists recognized his scientific foundation. The botanists at Bonn University analyzed the lotus leaf surfaces and many other plants using an electron micro-scanning system [14].

This spectrum resolves structures that are as small as $1-20 \mathrm{~nm}$ (one $\mathrm{nm}=$ billionth or $10^{-}$ ${ }^{9}$ meters). They found that self-cleansing is related to convex papillae on leaf surfaces covered with nanoscopic dimension wax crystals: approximately 10 to approximately $100 \mathrm{~nm}$.

The papilla significantly decreases the water droplet contact area. The droplet, for instance, by rain, cloud, or moisture, is dislocated and usually coalesce to a huge drop in the core of the surface of leaves that flows off with the leaf's swing. Wax consists of a combination of hydrocarbons of long-chain: alcohols, aldehydes, and triterpenes, both primary and secondary. When it is well researched in the lotus, the occurrence of water repellence and selfcleaning has become called the 'Lotus effect'.

Scientists studied about 13,000 plants. Mostly on surfaces of the plants over the ground, a wide variety of structures has been found $[14,15]$. 


\section{Water-Repellent Plant Surfaces Occurrence}

Importantly, most plants have water-repellent leaves in the wetlands. If this is not the case, the watering of the stomata on the upper (exposure) section of the floating leaves will interfere with gas exchange. Some other benefits of a surface with water repellents may be to reduce the chance of infection. Because the spores of some bacteria need free water and air for plant growth, it has evolved naturally to reduce the risk of attacking pathogenic bacteria and fungi by pasting wax molecules on cuticles (externally covered). Water repellence is not limited exclusively to plants. The insects with huge wings (such as butterflies and dragonflies) that cannot purify their flying structures by their legs are also realized. In this situation, the lotus effect acts not only to eliminate particulate matter but also for preserving the flight potential of insects $[13,16,17]$.

\section{Types of Coatings}

\subsection{Hydrophobic and superhydrophobic coatings (Lotus Effect).}

That hydrophobic coating's self-cleansing effect comes from Large contact angles with water; The water forming near-sphere droplets on these surfaces quickly roll away and with them moves dust and soil.

Before it would evaporate, polluted water that lands on the hydrophobic substrate is eliminated. The rolling flow of droplets is a crucial self-cleansing process and dynamic physical phenomena. A droplet rolls, the contact angles of a progressive or decreasing threestage interface between solid, liquid, and gas produce a deformation.

Methodology on how this deformation changes with the chemical and topological features of the surface is still evolving. Suppose drops are to roll with flexibility and at low surface inclination angles. In that case, deformation should be as close to zero as possible. Since drops roll-on extremely stable contact angle surfaces only, writers also only keep quoting a static contact angle for their surfaces.

The rolling movement clears the floor more quickly and is less likely to be left the dust away rather than the slipping action at lower touch angles. Thus, the highest static contact angle for a self-cleaning hydrophobic floor surface is the condition frequently mentioned over 160 degrees, with the rollover angle being very low. A surface with both properties is called superhydrophobic or ultra hydrophobic.

Ultrasonic surfaces have become the natural environment's self-clearing coatings: more than 200 plants can use rolling drops of water to maintain the "Lotus" plants in Asia clean, possibly the most popular one [18].

\subsection{Hydrophilic coatings}

In comparison to hydrophobics, scientists are searching for hydrophilic surfaces useful for self-cleaning applications in the presence of water. The dampness is elevated and the contact angle is about 0 .

So, rather than droplets, water lays on the surface. The surface is washed along with the photocatalysis and the surface is then filled with water to extract the dirt molleculations [19]. 


\section{Photocatalyst}

Subsequently, photocatalysts can break down mutual organic matters in the air like odor molecules, bacteria, and viruses. A photocatalytic semiconductor technique has shown great potential as a low price, environmentally friendly, and sustainable curing [20,21].

\subsection{Method for photocatalysis.}

In the availability of catalysts, photosynthesis is speeded up. Through using light from the sun, this mechanism breaks down the dirt molecules. The organic Pollutants can be transformed into air and water using photocatalytic reactions [22].

When a photocatalyst is emitted by light, usually ultraviolet light, the photocatalytic process starts. Electrons at the photocatalyst surface are stimulated with a power similar to or greater than the bandgap and leaving the valence band to go to the conduction band. The negative electrons charged $\left(\mathrm{e}^{-}\right)$in the conduction band stimulated pair in the surface, with the positively charged holes $\left(\mathrm{H}^{+}\right)$in the valence band. The produced pairs can be reunions and bind with other materials, which the photocatalyst absorbs [19,23].

The couples activate redox reactions onto the surface. The negatively charged ions and the oxygen combines into racial superoxide anions $\left(\mathrm{O}_{2}\right)$, while hydroxyl radicals $(\mathrm{OH})$ are produced by positively charged holes and water [22].

So many shaped highly activated oxygen molecules can ultimately oxidize organic compounds to carbon dioxide $\left(\mathrm{CO}_{2}\right)$ and water $\left(\mathrm{H}_{2} \mathrm{O}\right)$. The photocatalytic activity could then break down organic material, including particles of odorants, viruses, and bacteria in the air [24].

\subsection{Photocatalytic materials.}

\subsubsection{Titanium dioxide.}

Titanium dioxide $\left(\mathrm{TiO}_{2}\right)$ is a photocatalytic semiconductor and has proven to be an ideal catalyst for the visual degradation of dyes and other organic contaminants. Due to its different benefits, including non-toxicity, availability, cost efficiency, chemical constancy, and beneficial physical and chemical properties, are widely applied [19].

There are three crystalline phases in which titanium dioxide is present; rutile, anatase, and brookite [25].

In the case of pigments as sun blockers and paintings, the rutile between these three types is more reliable than the two others. The anatase has an open crystal-based structure, it is highly photocatalytic and often seemed to be the most active and the simplest to manufacture in semiconductor photochemistry [26].

In terms of heat, anatase and brookite will be rutile. There are band holes for either the anatase and the rutile. Their photoactive existence ensures the existence of radical species on their surfaces in the presence of sun and water [25].

$\mathrm{TiO}_{2}$ has become a product for industrial self-cleaning surfaces, including kitchen and bath ceramic tiles and garments, indoor air filters, and window glass $[18,19]$.

If the particle size of $\mathrm{TiO}_{2}$ decreases to nano, the photocatalytic behavior increases. Titania $\left(\mathrm{TiO}_{2}\right)$ nanoparticles with a cellulose or cotton surface have been merged, producing an occurrence of self-cleaning. In the latest items known as intelligent textiles, the manufacture of cotton textiles with a life cycle of between 25-50 washings or higher is a goal pursued by 
the textiles industry. So many experiments have shown that cotton textiles can be coated by $\mathrm{TiO}_{2}$ using various pretreatment methods and techniques, such as RF-plasma, MW-plasma, UV radiation, dip-pad-dry-cure, and dip-coating [25].

\subsubsection{Zinc oxide.}

Zinc oxide is another semi-conductive element that seems to be an alternative to $\mathrm{TiO} 2$ $(\mathrm{ZnO})$. Due to its non-toxic nature, cheap, and strong photochemical reactivity, the use of $\mathrm{ZnO}$ as degrading content for environmental contaminants has been widely discussed. $\mathrm{ZnO}$ was often mentioned to be more effective than $\mathrm{TiO}_{2}$. $\mathrm{ZnO}$ in powder form has mainly been used to degrade dyes found in effluent photocatalysis. Even so, after degradation, the $\mathrm{ZnO}$ powder has a recovery issue because some $\mathrm{ZnO}$ powder is lost when solutions have been drained. $\mathrm{ZnO}$ particles should especially be added to the material because it has the highest surface area to fix the issue. Such textiles with practical $\mathrm{ZnO}$ can be used for effluent and self-cleaning applications [25].

Zinc Oxide $(\mathrm{ZnO})$ and doped Iron zinc Oxide $(2 \% \mathrm{Fe}-\mathrm{ZnO})$ has been given great importance due to the physiological, chemical, and optic properties of the components that make them ideal for diversified catalytical purposes, photocatalysis, sensors, ultra-violet (UV) photodetectors, etc [27].

Different nanoparticles synthesis methods, including the sol-gel and hydrothermal processes, SILAR, CVDs, etc, have previously been published [2,28-35]. However, sol-gel is favored for greater photocatalytic action than all other methods. Similarly, this synthesized approach offers an economical resolution of agricultural wastewater cleaning [36-38]. There were quite a few attempts for the functionalization of $\mathrm{ZnO}$ textiles for self-cleaning [25].

\subsubsection{Other materials.}

Though many self-cleaning semiconductor analyses focus hard on UV-light irradiation of $\mathrm{TiO}_{2}$, other substances and techniques could be used. Over the years, some metal oxides and sulfides have been examined, such as $\mathrm{WO}_{3}, \mathrm{ZrO}_{2}, \mathrm{ZnO}$, and $\mathrm{CdS}$, as well as polyoxometalates, but no one has ever overcome $\mathrm{TiO}_{2}$ with light alone to enable the catalyst. But the semiconducting photocatalysis is affected via an electric field as an effectively electrochemical operation [18].

\section{Self-Cleaning on Fabric}

In daily human needs, textiles play a significant role. They are typically manufactured and used in clothing. In many other fields, like agricultural production, transport, construction materials, and healthcare, textile materials or fibers are also essential. The technical advancement of textiles is then enhanced to meet the needs of different industries. The characteristics and efficiency of textile fibers are important for the production and use of fabrics. Cloth finishing has often led to innovative technological features, which are important in various end-uses. New technologies variegation in the finishing industry focuses on the efficiency of fabrics and renders them practical in the field of chemistry linked to garment finishing that has been progressing and advancing. Recent scientific interests have grown exponentially with the use of nanomaterials in the textile industry. Nanotechnology has been shown to improve garment characteristics like the softness of the cloth, flexibility, 
breathability, water repulsion, delayed flame, and antimicrobial properties of fibers, films, and fabrics [39].

Textile finishing with inorganic nano-suspending colloidal nano-sols will create new materials wherein inorganic nanomaterials characteristics are passed only to the textile surface [40].

All has been done to create finished fabrics with several results once nanoparticles in textiles were introduced. This was primarily because fabrics of textiles consider one of the best surfaces for nanotechnology, and cotton fibers, commonly referred to as cotton fibers, have a wide area.

The strong fixation of nanoparticles to fabric surfaces is an important part of the nanotechnological operation in the textile industry. This means that the durability of the required characteristics is improved and nanoparticles are minimally lost to the atmosphere.

An optimum chemical integration among nanomaterials and even the textile surface must be obtained to ensure the application of nanoparticles. For this reason, A technique that utilizes covalent linkers is a widely used one [26].

The method of dip-pad-dry-curing also creates linkages among nanomaterials and a textile.

The authors tested the influence of nano $\mathrm{TiO} 2$ chemical treatment on the characteristics of cotton fabric. The cotton material was prepared by the pad-dry-cure process using nano $\mathrm{TiO}_{2}$ particles [41]. Functionalization of wool fabrics utilizing sol-gel low temp process with $\mathrm{TiO}_{2}$ and $\mathrm{TiO}_{2} / \mathrm{SiO}_{2}$ nanocomposite [42].

Self-cleaning textiles perform by using photocatalysts such as titanium dioxide and zinc oxide to introduce a photocatalytic response in the material. The textile that is covered with a thin layer of titanium dioxide molecule, this semiconductor, exposed to the sun, radiation with an energy equivalent or greater than the photocatalyst wavelength, stimulates electrons to the conductive band. Throughout the crystalline structure, only the excited electrons interact with oxygen atoms in the air, producing free-radical oxygen. Such oxygen atoms are powerful oxidants that can destroy most carbonic substances via the oxidation process. This process breaks down the organic materials (i.e., toxins and microscopic creatures ) into substances such as carbon dioxide and water [24].

In addition to high separation and the structural effects of the amorphous silica compound, the cotton fabric $\mathrm{TiO}_{2}-\mathrm{SiO}_{2}$ treated exhibited an excellent photocatalytic activity above $\mathrm{TIO}_{2}$ cotton alone $[43,44]$.

Experts have confirmed that cotton textiles can be linked to $\mathrm{TiO}_{2}$ via chemical holes. A coating process was easy and non-toxic surfactants had been used. $\mathrm{TiO}_{2}$ cotton textiles have a steadily self-cleaning effect and caused any chromophore(s) of wine to be slightly removed by daylight, which shows a stable long-term efficiency [19].

Experts also defined that the degree of self-cleaning in cross-linked textiles is higher than in non-cross-linked cured substances. This results in a higher amount and more reliable distribution of titanium components over cotton surfaces in the cross-linking process than in the non-crosslink process. These higher levels of self-cleaning are done [45].

\section{Summary}

In different industries, the idea of self-cleaning provides several benefits. Self-cleansing fabric, in particular, that, due to times, materials, energy reduction, and thus cost-effectiveness in manufacturing, has a huge potential for improving products and the textile industry, health 
industry. Besides, this technology encompasses environmental characteristics as cleaning activities are effectively reduced, a substantial volume of water and energy are conserved, as well as time and laundering costs are saved.

This review article covers different research work carried out in the last 10 years on hydrophilic and hydrophobic surfaces.

Another difficulty is the 'peeling off' impact in creating competent self-cleaning surfaces in this paper. Self-cleaning surfaces are ideal for many areas ranging from the glass industry to the textile sector and are a promising area for interesting research.

\section{Funding}

This research received no external funding.

\section{Acknowledgments}

The authors are gratefully grateful to acknowledge the Faculty of Applied Arts, Benha University, for the facilities provided. Thankful are also acknowledge to National Research Centre (NRC).

\section{Conflicts of Interest}

The authors declare no conflict of interest.

\section{References}

1. Abo-Shosha, M.H.; Nassar, F.A.; Haggag, K.; El-Sayed, Z.; Hassabo, A.G. Utilization of some fatty acid/peg condensates as emulsifiers in kerosene paste pigment printing. Research Journal of Textile and Apparel $\mathbf{2 0 0 9 ,}$ 13, 65-77, http://dx.doi.org/10.1108/RJTA-13-01-2009-B007.

2. El-Zawahry, M.M.; Hassabo, A.G.; Abdelghaffar, F.; Abdelghaffar, R.A.; Hakeim, O.A. Preparation and use of aqueous solutions magnetic chitosan / nanocellulose aerogels for the sorption of reactive black 5. Biointerface Research in Applied Chemistry 2021, 11, 12380 - 12402, https://doi.org/10.33263/BRIAC114.1238012402.

3. El-Zawahry, M.M.; Abdelghaffar, F.; Abdelghaffar, R.A.; Hassabo, A.G. Equilibrium and kinetic models on the adsorption of reactive black 5 from aqueous solution using eichhornia crassipes/chitosan composite. Carbohydr. Polym. 2016, 136, 507-515, http://dx.doi.org/10.1016/j.carbpol.2015.09.071.

4. Ibrahim, N.A.; El-Sayed, Z.M.; Fahmy, H.M.; Hassabo, A.G.; Abo-Shosha, M.H. Perfume finishing of cotton / polyester fabric cross-linked with dmdheu in presence of some softeners. RJTA 2013, 17, 58-63, https://doi.org/10.1108/RJTA-17-04-2013-B007.

5. Mohamed, A.L.; El-Naggar, M.E.; Shaheen, T.I.; Hassabo, A.G. Novel nano polymeric system containing biosynthesized core shell silver/silica nanoparticles for functionalization of cellulosic based material. Microsys. Technol. 2016, 22, 979-992, http://doi.org/10.1007/s00542-015-2776-0.

6. Mohamed, A.L.; Er-Rafik, M.; Moller, M. Suitability of confocal raman microscopy for monitoring the penetration of pdms compounds into cotton fibres. Carbohydr. Polym. 2013, 96, 305-313, http://dx.doi.org/10.1016/j.carbpol.2013.03.087.

7. Mohamed, A.L.; Er-Rafik, M.; Moller, M. Supercritical carbon dioxide assisted silicon based finishing of cellulosic fabric: A novel approach. Carbohydr. Polym. 2013, 98, 1095-1107, http://dx.doi.org/10.1016/j.carbpol.2013.06.027.

8. Waly, A.I.; Abou-Zeid, N.Y.; Marie, M.M.; El-Sheikh, M.A.; Mohamed, A.L. Special finishing of cotton to impart flame-retardancy, easy care finishing and antimicrobial properties. RJTA 2009, 13, 10-26, https://doi.org/10.1108/RJTA-13-03-2009-B002.

9. Waly, A.I.; Marie, M.M.; Abou-Zeid, N.Y.; El-Sheikh, M.A.; Mohamed, A.L. Processes of dyeing, finishing and flame retardancy of cellulosic textiles in the presence of reactive tertiary amines. RJTA 2012, 16, 66 - 84, https://doi.org/10.1108/RJTA-16-03-2012-B007. 
10. Prathapan, R.; Venkatesan, A.G.; Nair, S.; Nair, S. A review on 'self-cleaning and multifunctional materials'. Journal of Materials Chemistry A: Materials for Energy and Sustainability 2014, 2, 14773-14797, https://doi.org/10.1039/c4ta02542c.

11. Zhu, C.; Shi, J.; Xu, S.; Ishimori, M.; Sui, J.; Morikawa, H. Design and characterization of self-cleaning cotton fabrics exploiting zinc oxide nanoparticle-triggered photocatalytic degradation. Cellulose 2017, 24, 2657-2667, https://doi.org/10.1007/s10570-017-1289-7.

12. Guan, Y.; Yu, C.; Zhu, J.; Yang, R.; Li, X.; Wei, D.; Xu, X. Design and fabrication of vapor-induced superhydrophobic surfaces obtained from polyethylene wax and silica nanoparticles in hierarchical structures. RSC Adv. 2018, 8, 25150-25158, https://doi.org/10.1039/c8ra01666f.

13. Khattab, T.A.; Mohamed, A.L.; Hassabo, A.G. Development of durable superhydrophobic cotton fabrics coated with silicone/stearic acid using different cross-linkers. Materials Chemistry and Physics 2020, 249, https://doi.org/10.1016/j.matchemphys.2020.122981.

14. Barthlott, W.; Neinhuis, C. Purity of the sacred lotus, or escape from contamination in biological surfaces. Planta 1997, 202, 1-8, https://doi.org/10.1007/s004250050096.

15. Forbes, P. Self-cleaning materials. Sci Am 2008, 299, 88-95, https://doi.org/10.1038/scientificamerican0808-88.

16. Karthick, B.; Maheshwari, R. Lotus-inspired nanotechnology applications. Resonance 2008, 13, 1141-1145, https://doi.org/10.1007/s12045-008-0113-y.

17. Mohamed, A.L.; Hassabo, A.G.; Nada, A.A.; Abou-Zeid, N.Y. Properties of cellulosic fabrics treated by waterrepellent emulsions. Indian J. Fibre Text. Res. 2017, 42, 223-229.

18. Parkin, I.P.; Palgrave, R.G. Self-cleaning coatings. Journal of Materials Chemistry 2005, 15, 1689-1695, https://doi.org/10.1039/B412803F.

19. Saad, S.; Mahmed, N.; Abdullah, M.M.A.B.; Sandu, A.V. Self-cleaning technology in fabric: A review. IOP Conference Series: Materials Science and Engineering 2016, 133, 012028, https://doi.org/10.1088/1757899X/133/1/012028.

20. Chaudhari, S.B.; Mandot, A.A.; Patel, B.H. Effect of nano tio2 pretreatment on functional properties of cotton fabric. International Journal of Engineering Research and Development 2012, 1, 24-29.

21. Rehan, M.; Elshemy, N.S.; Haggag, K.; Montaser, A.S.; Ibrahim, G.E. Phytochemicals and volatile compounds of peanut red skin extract: Simultaneous coloration and in situ synthesis of silver nanoparticles for multifunctional viscose fibers. Cellulose 2020, 27, 9893-9912, https://doi.org/10.1007/s10570-020-03452-8.

22. kumar, B.S. Self-cleaning finish on cotton textile using sol-gel derived tio2 nano finish. Journal of Polymer and Textile Engineering 2015, 2, 1-5, https://doi.org/10.9790/019X-0210105.

23. Anwar, Y.; Alghamdi, K.M. Imparting antibacterial, antifungal and catalytic properties to cotton cloth surface via green route. Polym. Test. 2020, 81, 106258, https://doi.org/10.1016/j.polymertesting.2019.106258.

24. Samal, S.S.; Jeyaraman, P.; Vishwakarma, V. Sonochemical coating of ag-tio2 nanoparticles on textile fabrics for stain repellency and self-cleaning- the indian scenario: A review. Journal of Minerals and Materials Characterization and Engineering 2010, 9, 519-525, https://doi.org/10.4236/jmmce.2010.96036.

25. Karimi, L.; Mirjalili, M.; Yazdanshenas, M.; Nazari, A. Effect of nano tio2 on self-cleaning property of crosslinking cotton fabric with succinic acid under uv irradiation. Photochem Photobiol 2010, 86, 1030-1037, https://doi.org/10.1111/j.1751-1097.2010.00756.x.

26. Asokan, A.; Ramachandran, T.; Ramaswamy, R.; Koushik, C.V.; Muthusamy, M. Preparation and characterization of zinc oxide nanoparticles and a study of the antimicrobial property of cotton fabric treated with the particles. JTATM 2010, 6 .

27. Isai, K.A.; Shrivastava, V.S. Photocatalytic degradation of methylene blue using zno and $2 \%$ fe-zno semiconductor nanomaterials synthesized by sol-gel method: A comparative study. SN Applied Sciences 2019 , 1, 1247, https://doi.org/10.1007/s42452-019-1279-5.

28. Zayed, M.; Othman, H.; Ghazal, H.; Hassabo, A.G. Psidium guajava leave extract as reducing agent for synthesis of zinc oxide nanoparticles and its application to impart multifunctional properties for cellulosic fabrics. Biointerface Research in Applied Chemistry 2021, $11, \quad 13535 \quad$ - 13556, https://doi.org/10.33263/BRIAC115.1353513556.

29. Mohamed, A.L.; El-Naggar, M.E.; Hassabo, A.G. Preparation of hybrid nanoparticles to enhance the electrical conductivity and performance properties of cotton fabrics. Journal of Materials Research and Technology 2021, https://doi.org/10.1016/j.jmrt.2021.02.035.

30. Hassabo, A.G.; Mohamed, A.L. Novel flame retardant and antibacterial agent containing mgo nps, phosphorus, nitrogen and silicon units for functionalise cotton fabrics. Biointerface Research in Applied Chemistry 2019, 9, 4272 - 4278, https://doi.org/10.33263/BRIAC95.272278. 
31. Hassabo, A.G.; El-Naggar, M.E.; Mohamed, A.L.; Hebeish, A.A. Development of multifunctional modified cotton fabric with tri-component nanoparticles of silver, copper and zinc oxide. Carbohydr. Polym. 2019, 210, 144-156, https://doi.org/10.1016/j.carbpol.2019.01.066.

32. Ibrahim, N.A.; Nada, A.A.; Eid, B.M.; Al-Moghazy, M.; Hassabo, A.G.; Abou-Zeid, N.Y. Nano-structured metal oxides: Synthesis, characterization and application for multifunctional cotton fabric. Advanc. Nat. Sci.: Nanosci. Nanotechnol. 2018, 9, 035014, https://doi.org/10.1088/2043-6254/aadc2c.

33. Mohamed, A.L.; Hassabo, A.G. Composite material based on pullulan/silane/zno-nps as ph, thermo-sensitive and antibacterial agent for cellulosic fabrics. Advances in Natural Science: Nanoscience and Nanotechnolgy 2018, 9, 045005, https://doi.org/10.1088/2043-6254/aaeee0.

34. Jose Varghese, R.; Zikalala, N.; Sakho, E.H.M.; Oluwafemi, O.S. Green synthesis protocol on metal oxide nanoparticles using plant extracts. In Colloidal metal oxide nanoparticles 2020, 67-82, http://doi.org/10.1016/b978-0-12-813357-6.00006-1.

35. Joshi, N.C.; Malik, S.; Gururani, P. Utilization of polypyrrole/zno nanocomposite in the adsorptive removal of cu2+, pb2+ and cd2+ ions from wastewater. Letters in Applied NanoBioScience 2021, 10, 2339 - 2351, https://doi.org/10.33263/LIANBS103.23392351.

36. Jurablu, S.; Farahmandjou, M.; Firoozabadi, T.P. Sol-gel synthesis of zinc oxide (zno) nanoparticles: Study of structural and optical properties \%j journal of sciences, islamic republic of iran. 2015, 26, 281-285.

37. Suresh Babu, K..; Narayanan, V. Hydrothermal synthesis of hydrated zinc oxide nanoparticles and its characterization. Chem Sci Trans 2013, 2, S33-S36, https://doi.org/10.7598/cst2013.4.

38. Protasova, L.N.; Rebrov, E.V.; Choy, K.L.; Pung, S.Y.; Engels, V.; Cabaj, M.; Wheatley, A.E.H.; Schouten, J.C. Zno based nanowires grown by chemical vapour deposition for selective hydrogenation of acetylene alcohols. Catalysis Science \& Technology 2011, 1, 768-777, https://doi.org/10.1039/C1CY00074H.

39. Sawhney, A.P.S.; Condon, B.; Singh, K.V.; Pang, S.S.; Li, G.; Hui, D. Modern applications of nanotechnology in textiles. 2008, 78, 731-739, https://doi.org/10.1177/0040517508091066.

40. Ortelli, S.; Costa, A.; Dondi, M. Tio2 nanosols applied directly on textiles using different purification treatments. Materials 2015, 8, 7988-7996, https://doi.org/10.3390/ma8115437.

41. Vodisek, N.; Suligoj, A.; Korte, D.; Lavrencic Stangar, U. Transparent photocatalytic thin films on flexible polymer substrates. Materials (Basel) 2018, 11, https://doi.org/10.3390/ma11101945.

42. Pakdel, E.; Daoud, W.A.; Wang, X. Self-cleaning and superhydrophilic wool by tio2/sio2 nanocomposite. Appl. Surf. Sci. 2013, 275, 397-402, https://doi.org/10.1016/j.apsusc.2012.10.141.

43. Yuranova, T.; Mosteo, R.; Bandara, J.; Laub, D.; Kiwi, J. Self-cleaning cotton textiles surfaces modified by photoactive sio2/tio2 coating. J. Mol. Catal. A: Chem. 2006, 244, 160-167, https://doi.org/10.1016/j.molcata.2005.08.059.

44. El-Naggar, M.E.; Hassabo, A.G.; Mohamed, A.L.; Shaheen, T.I. Surface modification of sio2 coated zno nanoparticles for multifunctional cotton fabrics. J. Colloid Interface Sci. 2017, 498, 413-422, http://dx.doi.org/10.1016/j.jcis.2017.03.080.

45. Mirjalili, M.; Karimi, L. Photocatalytic degradation of synthesized colorant stains on cotton fabric coated with nano tio2. Journal of Fiber Bioengineering and Informatics 2011, 3, 208-215, https://doi.org/10.3993/jfbi03201. 